\title{
CD44 and CD44 Variant 6 in Children with Acute Lymphoblastic Leukemia
}

Ahmad A Omran ${ }^{1}$, Esmat A Elsharkawy ${ }^{1}$, Ayman G Ghobrial ${ }^{1}$, Hosny B Hamed ${ }^{2}$, Waleed M Abd el Hameed ${ }^{1 *}$, Nagwa I Okaily ${ }^{1}$ and AbdelAzeem M. El-Marazy

${ }^{1}$ Clinical Pathology Department, Faculty of Medicine, Minia University, Egypt

${ }^{2}$ Clinical Pathology Department, South Egypt Cancer institute Assiut University, Egypt

${ }^{3}$ Pediatric and neonatology Department, Faculty of Medicine, Minia University, Egypt

\begin{abstract}
Background and objectives: Acute lymphoblastic leukemia (ALL) is a malignant disorder of lymphoid progenitor cells. Many prognostic factors are important for therapeutic assignment. The cell adhesion molecule CD44 is involved in pathologic activities of tumour cells and hematological malignancies. CD44v6 is an important isoform of CD44 family. It plays an important role in the growth and metastasis development in some hematological malignancies The aim of this study is to detect CD44 and CD44v6 expression in children with acute lymphoblastic leukemia and to correlate them with prognosis and other standard prognostic factors for ALL.
\end{abstract}

Subjects and methods: The study carried out on 57 children divided into: group I included 40 newly diagnosed children with acute lymphoblastic leukemia who were followed up for one year and group II 17 apparently healthy children of matched age and sex (as control group). Each child was subjected to complete history taking, clinical examination, laboratory investigations in the form of routine investigations; CBC, Leishman-stained peripheral blood smears, LDH. Bone marrow aspiration, Myeloperoxidase-stained peripheral blood, bone marrow smears, Immunophenotyping on BM/PB samples determined by Flowcytometer for routine panel of acute leukemia. Special investigations in the form of; flowcytometeric analysis of CD44 and CD44v6 mRNA expression by quantitative RTPCR were done for all children.

Results: CD44 expression was significantly higher in group I than group II $(\mathrm{P}=0.001)$ while there was no significant difference between CD44v6 in group I and group II . Significant positive correlation between CD44\% and LDH level, total leucocytic count and bone marrow blast cell ( $r=0.64, P=0.001$ \& $r=0.62, P=0.001$ \& $r=0.92, P=0.001$ ) respectively, However there was statistically significant negative correlation between $C D 44 \%$, hemoglobin(HB) level and platelet count $(r=-0.93, P=0.001 \& r=-0.92, P=0.001)$ respectively. CD44\%, white blood cell count, Percentage of cases with lymphadenopathy and/or splenomegaly was significantly higher in children with unfavorable outcome. There was non significant difference between favorable and those with unfavorable outcome as regards $\mathrm{CD} 44 \mathrm{v} 6(\mathrm{P}=0.1)$ and there was no correlation between $\mathrm{CD} 44 \mathrm{v} 6$, HB level, platelet count, WBCs count, LDH level and B.M. blast cells in ALL patients.

Conclusion: CD44 but not CD44v6 expression can serve as a powerful prognostic marker in childhood ALL associated with bad prognosis. CD44 high expression identifies high risk subgroup.

Keywords: Acute lymphoblastic leukemia (ALL) ; Prognostic factors; CD44; CD44v6

\section{Introduction}

Acute lymphoblastic leukemia (ALL) is a malignant disorder of lymphoid progenitor cells that proliferate and replace the normal hematopoietic cells of the bone marrow. These lymphoblasts replace the normal bone marrow elements resulting in marked decrease in the production of normal blood cells [1].

A number of clinical and biological features at the time of presentation are relevant to the prognosis and affect the response to treatment [2]. These prognostic factors include age, gender, number of bone marrow blasts, white blood cell (WBC) and platelet number, cytogenetic abnormalities, extramedullary involvement (EMI), and immune phenotype. The prognostic relevance of immune phenotype and the expression of various markers in ALL have been documented and provide important information as regards classification, diagnosis and treatment $[3,4]$.

CD44 is an adhesion molecule, a glycoprotein, which is expressed by $\mathrm{B}$ and $\mathrm{T}$ lymphocytes, that mediates cell attachment to extracellular matrix components and adhesion to endothelial cells. Its levels of expression vary between cell types and their activation state [5].
CD44 variants $(\mathrm{CD} 44 \mathrm{v})$ are mainly expressed on epithelial cells, encoding amino acids with extensive glycosylation sites and chondroitic acid-binding sites. Splicing in continuous or septal way, different variable region exons combination encode different CD44 molecules. At present, there are more than 10 kinds of CD44v in many cell lines detected by polymerase chain reaction. Alternative splicing is the basis for the structural and functional diversity of this protein, and may be related to tumor metastasis [6].

CD44v6 is found to confer metastatic behavior of tumor cells and plays an important role in pathophysiology and prognosis. In hematopoietic malignancies increased gene expression of exons v6 and $\mathrm{v} 9$ is associated with poor prognosis in non-Hodgkin lymphoma and

*Corresponding author: Waleed M.Abd el Hameed, Clinical Pathology Department, Faculty of Medicine, Minia University, Egypt, Tel: 01005200719; E-mail: waleed_mahmoud72@yahoo.com

Received November 12, 2015; Accepted December 01, 2015; Published December 08, 2015

Citation: Omran AA, Elsharkawy EA, Ghobrial AG, Hamed HB, Abd el Hameed WM, et al. (2015) CD44 and CD44 Variant 6 in Children with Acute Lymphoblastic Leukemia. J Cancer Sci Ther 7: 375-378. doi:10.4172/1948-5956.1000377

Copyright: (c) 2015 Omran AA, et al. This is an open-access article distributed under the terms of the Creative Commons Attribution License, which permits unrestricted use, distribution, and reproduction in any medium, provided the original author and source are credited. 
Citation: Omran AA, Elsharkawy EA, Ghobrial AG, Hamed HB, Abd el Hameed WM, et al. (2015) CD44 and CD44 Variant 6 in Children with Acute Lymphoblastic Leukemia. J Cancer Sci Ther 7: 375-378. doi:10.4172/1948-5956.1000377

myeloma, and exon v6 with poor prognosis in acute myeloid leukemia [7].

\section{Subjects and Methods}

The study population included 57 children; Group I included 40 newly diagnosed children with acute lymphoblastic leukemia (their ages ranged from 3 to 12 years and included 21 males and 19 females) selected from oncology out-patient clinic of Minia Oncology Center, Minia University hospital and South Egypt Cancer Institute during the period from December 2012 to June 2013 and followed up for one year. Group II included 17 apparently healthy children matched for age and sex with the patient group as a control group (their ages ranged from 4 to 12 years and included 9 males and 8 females).

Both patients and control groups were subjected to the following: complete history taking, clinical examination and laboratory investigations in the form of: Complete blood count determined by automated cell counter sysmex kx-21N (TAO Medical Incorporation, Japan), Examination of Leishman-stained peripheral blood smears for differential leucocytic count. Abdominal ultrasonography, bone marrow aspiration and, assessment of blast cell number and morphology and myeloperoxidase-stained peripheral blood were done for patients only. Bone marrow aspiration was done by marrow puncture needles (Klima type) either from anterior or posterior superior iliac spine and examination of leishman-stained smears. Immunophenotyping was done on BM/PB samples determined by Flowcytometer (FACS Calibur BD bioscience, USA) for routine panel of acute leukemia, LDH determined by Elitech Clinical Systems, Puteaux France. Flow cytometeric analysis for CD44 and CD44v6 mRNA expression by quantitative RT-PCR(using Light Cycler Roche, Germany) .

All analyses were performed with version 19 of Statistical Package of Social Science (SPSS).Qualitative data were expressed as proportions, while quantitative data were expressed as mean \pm standard deviation (SD). Qualitative data were analyzed by Chi square $\left(\chi^{2}\right)$ test. Comparisons between groups for normally distributed quantitative data were performed by Student's t-test. Correlations between variables were obtained by Pearson's test. For all analyses, statistical significance was defined as $\mathrm{p}$ values less than 0.05 .

\section{Results}

\section{According to immunophenotyping (Table 1-3)}

Group I subdivided into: (T- Lineage ALL (Ia included 4 patients) and B-lineage ALL (Ib included 36 ) which subdivided into: "Early pre-B (Ib1 included one patient), Common B (Ib2 included 14 patients), Pre-B (Ib3 included 20 patients) and B-ALL (Ib4" included one patient). There were no statistically significant differences between group Ib2 $(n=14)$ and group Ib3 $(n=20)$ except for WBCs count which was significantly higher in group Ib3 $\left(\mathrm{p}=0.04^{\star}\right)$.

\section{According to expression of CD44}

Group I subdivided into: (Negative (Ix), Weak positive (Iy), Strong positive (Iz)).

There were no statistically significant differences between patient subgroups regarding age, sex, splenomegaly and hepatomegaly. However there was border line statistically significant increase in percentage of cases with lymphadenopathy in group Iz compared to group Ix and and in group Iz compared to group Iy.

Concerning the outcome, there was statistically significant increase in relapsed and died patients in group Iz, group Iy when compared to group Ix.

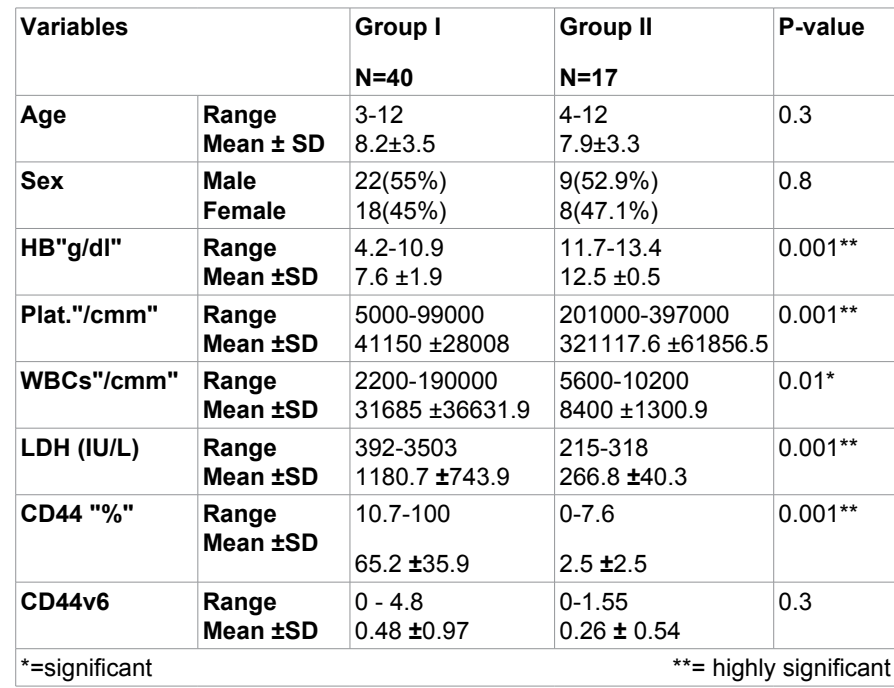

Table 1: Demographic and laboratory data of studied groups.

\begin{tabular}{|l|l|l|l|}
\hline Variables & $\begin{array}{l}\text { Favorable } \\
\mathbf{N}=16\end{array}$ & $\begin{array}{l}\text { Unfavorable } \\
\mathbf{N = 2 4}\end{array}$ & $\mathbf{P}$ \\
\hline Age (year) & $6.7 \pm 3.6$ & $7.1 \pm 3.4$ & 0.7 \\
\hline Sex Male & $\begin{array}{l}7(43.8 \%) \\
9(56.2 \%)\end{array}$ & $\begin{array}{l}15(62.5 \%) \\
9(37.5 \%)\end{array}$ & 0.2 \\
\hline Female & $6(37.5 \%)$ & $18(75 \%)$ & $0.008^{*}$ \\
\hline Lymphadenopathy & $6(37.5 \%)$ & $14(58.3 \%)$ & 0.09 \\
\hline Hepatomegaly & $6(37.5 \%)$ & $20(83.3 \%)$ & $0.001^{* *}$ \\
\hline Splenomegaly & $7.4 \pm 1.5$ & $7.7 \pm 2.2$ & 0.6 \\
\hline HB (g/dl) & $51187.5 \pm 28407.1$ & $34458.3 \pm 26213.1$ & 0.06 \\
\hline Plat. Count (/cmm) & $13375 \pm 10157.3$ & $42633.3 \pm 42294.7$ & $0.01^{*}$ \\
\hline WBCs count (/cmm) & $28.4 \pm 26.5$ & $89.7 \pm 12.4$ & $0.001^{* *}$ \\
\hline CD44\% & & & \\
\hline Immunophyontyping & 0 & $4(16.7 \%)$ & \\
\hline T- ALL & 0 & $1(4.2 \%)$ & 0.3 \\
\hline Early pre B & $7(29.2 \%)$ & \\
\hline $\begin{array}{l}\text { Common B } \\
\text { PreB }\end{array}$ & $\begin{array}{l}11(45.8 \%) \\
\text { B-ALL }\end{array}$ & $1(4.2 \%)$ & \\
\hline CD44 V6 & 0 & $0.6 \pm 1.2$ & 0.1 \\
\hline & $0.19 \pm 0.4$ & & \\
\hline
\end{tabular}

Table 2: Comparison between favorable \& Unfavorable outcome in ALL patients.

\begin{tabular}{|l|l|l|}
\hline Variables & $\mathbf{r}$ & $\mathbf{P}$ \\
\hline Age (years) & -0.13 & 0.4 \\
\hline LDH (IU/L) & 0.64 & $0.001^{* *}$ \\
\hline $\mathbf{H b}(\mathbf{g} /$ dl) & -0.93 & $0.001^{* *}$ \\
\hline Plat.(/cmm) & -0.92 & $0.001^{* *}$ \\
\hline WBCs $(/ \mathbf{c m m})$ & 0.62 & $0.001^{* *}$ \\
\hline Bone marrow blast\% & 0.92 & $0.001^{* *}$ \\
\hline CD44 V 6 & 0.25 & 0.1 \\
\hline *=significant & & **= highly significant \\
\hline
\end{tabular}

Table 3: Correlation between CD44 and studied parameters in ALL patients.

There was no statistically significant differences between patient subgroups regarding HB level, WBCs count, CD44v6 and Immunophenotyping, however there was statistically significant decrease in platelet count and increase in LDH level in group Iz compared to group Ix .

\section{According to expression of CD44v6}

Group I subdivided into: (Negative (In), positive (Io)). 
There was no statistically significant differences between patient subgroups except for increase percentage of cases with splenomegaly in group Io than in group In $\left(\mathrm{P}=0.01^{\star}\right)$.

\section{Discussion}

Acute leukemia is the commonest cancer affecting children, with acute lymphoblastic leukemia (ALL) being more common than acute myeloid leukemia (AML). The overall outcome of childhood ALL is generally favorable, with cure rates now exceeding $80 \%$ [8]. Despite this improvement, however, about $20-25 \%$ of the patients still relapse [9].

The majority of patients experiencing disease relapse cannot be adequately assessed for their chance of experiencing relapse at diagnosis. Immunophenotypic and cytogenetic prognostic markers for these patients offers the possibility to reassign them to a lower or higher risk grouping [10].

In the present study there were $22(55 \%)$ males and $18(45 \%)$ females, these results are compatible with $\mathrm{Wu}$ et al. [11], Reichard et al. [12] and Stacy and Patrick [13] who reported increase percentage of male than female in ALL patients.

LDH level in this study was significantly higher in ALL patients compared to control group. The results agreed with Hafiz and Mnnan [14], and Hunger et al. [15] who reported that early measurement of serum LDH could be useful in identifying response to chemotherapy.

The majority of patients,both children and adults, with ALL are of B-lymphoid origin. The B lymphoblastic leukemia is classified as precursor B leukemia (B-ALL) since the blast cells are neoplastic counterparts of normal B-cell precursors [16]. The classification into $\mathrm{B}-$ and T-ALL is important for risk stratification and treatment [17].

Immunophenotyping in the present study showed that $50 \%$ of patients were pre-B-ALL, $2.5 \%$ were mature B-ALL, early pre B $2.5 \%$, Common B 35\% (total: 90\%) and 10\% were T-ALL. This agreed with the study done by Zhang et al. [18] who found on their study on 139 ALL children, there were 103 cases (74.1\%) of B-ALL, 24 cases (17.3\%) of T-ALL as it was previously reported in other populations in studies done by Bachir et al. [19] who found on their study on 279 patients below the age of 18 years with newly diagnosed ALL that $78.85 \%$ of patients have B-cell acute lymphoblastic leukemia "B-ALL" and $21.15 \%$ of patients with acute lymphoblastic leukemia have" T-ALL" and also Supriyadi et al. [20] found in their study on 381 children with acute lymphoblastic leukemia of them $83 \%$ were B-lineage ALL and $17 \%$ T-lineage ALL .

Shrestha et al. [21] and Shushma et al. [22] reported that common ALL is a large group, which represents the majority of childhood ALL which was in disagreement with this study, this may be due to different number of cases or a variation in age range in the patient group.

It was found that there was no significant difference between B-ALL subtypes except in relation to leucocytic count which was higher in pre-B-ALL patients. This data was in line with Ramyar et al. [23] who reported an unfavorable prognosis for the pre-B group.

In tIn this study, $82.5 \%$ of ALL patients positively expressed CD44, these was slightly higher than those reported by Guoqiang et al. [24] who encountered CD44 expression in $77 \%$ and $76.8 \%$ of ALL patients respectively, but slightly lower than Ulrike et al. [5] who reported CD44 expression in $90.3 \%$ of ALL patients .

According to the relationship between CD44 expression and various studied standard prognostic factors, there were significant positive correlations between CD44 level and LDH level, white blood cells, bone marrow blast cells in ALL patients. However there were significant negative correlations between CD44 level and both of hemoglobin level and platelet count .

This was in agreement with Ahmed and Hassab [25] who made their study on 30 newly diagnosed ALL pediatric patients for CD44 expression by flow cytometry and correlated it to age, sex, TLC, $\mathrm{HB}$, platelet count, blast \% in peripheral blood and bone marrow, immunophenotyping and LDH.

These results came in contrast to Kamazani et al. [26] who reported that the expression of CD44 had no statistical association with any of standard prognostic markers.

It was found that CD44 was significantly higher in ALL patients with lymphadenopathy. Similarly it was found that CD44 was significantly higher in ALL patients with splenomegaly. These results were in agreement with those reported by El-sharkawy et al. [27] and Lubomir et al. [28] who found that the high expression of CD44s was associated with high tumour burden (i.e lymphadenopathy and organomegally). Williams et al. [6] explain that by the assumption that CD44 being an adhesion molecule, may be involved in the pathogenesis of a high tumor burden .

Khan et al. [10] presented the first large study examining the predictive value of CD44 protein expression on the outcome of treatment for children with ALL and its expression may serve as a new prognostic factor in childhood ALL, and that analysis for its expression may contribute to improve the management of ALL patients who lack prognostic cytogenetics.

Follow up of all patients showed that the percentage of CD44 expression in patients who had favorable outcome complete remission (CR) was $(28.4 \%)$ while in patients who had unfavorable outcome (incomplete remission, relapse and death) were (89.7\%). This was confirmed by a study done by Khan et al. [10].

The present study showed a highly significant association between the CD44 expression and unfavorable prognosis This observation was noticed by Theodora and Evangelia [29] who demonstrated that CD44 induce tumor growth, survival as well as cancer cell invasion.

In this study, according to expression of CD44, 65\% of patients were strongly positive while $17.5 \%$ patients were weak positive and the remaining patients $17.5 \%$ showed negativity for CD44 and when comparing these groups with each other's it was found that there was statistically significant decrease in platelet count, increase in LDH level, increase in percentage of lymphadenopathy and unfavorable outcome in strongly positive cases. Zac et al. [30] also showed the association between the high +ve CD44 expression with poor clinical outcome.

In contrast to this study Kamazani et al. [4] reported no significant correlation between CD44 expression and well-established risk factors such as age, WBC count, central nervous system involvement and chromosomal abnormalities.

Concerning CD44V6, the present study reported that there was no significant difference concerning CD44v6 expression between patients and controls and there was non-significant correlation between CD44v6 and CD44 level in ALL patients and that there was no significant difference between favorable and unfavorable prognosis as regard expression level.

These results agreed with Khan et al. [10] who reported that no 
Citation: Omran AA, Elsharkawy EA, Ghobrial AG, Hamed HB, Abd el Hameed WM, et al. (2015) CD44 and CD44 Variant 6 in Children with Acute Lymphoblastic Leukemia. J Cancer Sci Ther 7: 375-378. doi:10.4172/1948-5956.1000377

correlation between total CD44 protein expression levels and CD44v6 protein or mRNA expression levels, and that CD44V6 expression was not associated with poor outcome.

This was in disagreement with Bendall et al. [31], Kyueng et al. [32] and Todaro et al. [33] who reported That CD44v6 expression is correlated directly with poor survival. The discrepancy between these studies is likely due to different number of cases.

\section{Conclusions}

In conclusion, strong CD44 expression appears to be a powerful prognostic indicator in children with ALL while CD44 Variant 6 had no role in these children. CD44 is correlated well with the standard poor prognostic markers. Analysis of CD44 expression in addition to other standard prognostic markers at diagnosis may pave the way to improve the outcome.

\section{References}

1. Gowda C, Dovat S (2013) Genetic targets in pediatric acute lymphoblastic leukemia. Adv Exp Med Biol 779: 327-340.

2. Amirghofran Z, Daneshbod Y, Gholijani N, Esmaeilbeig M (2011) The influence of $\mathrm{Bcl}-2$ and myeloid antigen expression on response to therapy in childhood acute lymphoblastic leukemia. Arch Iran Med 14: 170-174.

3. Fathi M, Amirghofran Z, Shahriari M (2012) Soluble Fas and Fas ligand and prognosis in children with acute lymphoblastic leukemia. Med Oncol 29: 20462052.

4. Kamazani FM, Bahoush GR, Aghaeipour M, Vaeli S, Amirghofran Z (2013) CD44 and CD27 expression pattern in B cell precursor acute lymphoblastic leukemia and its clinical significance. Med Oncol 30: 359

5. Ulrike E, Amelie P, Xiaoyu G, Markus W, Margot Z (2014) CD44 standard and CD44v10 isoform expression on leukemia cells distinctly influences niche embedding of hematopoietic stem cells. Journal of Hematology \& Oncology 7: 29

6. Williams K, Motiani K, Giridhar PV, Kasper S (2013) CD44 integrates signaling in normal stem cell, cancer stem cell and (pre)metastatic niches. Exp Biol Med (Maywood) 238: 324-338.

7. Hao Q, Liguan X, Peixue L, Samuel W, Yongkui J (2012) CD44 ligation with A3D8 antibody induces apoptosis in acute myeloid leukemia cells through binding to CD44s and clustering lipid rafts. Cancer Biol Ther 13: 1276-1283.

8. Maria K, Despoina C, Chrysoula P, Georgia M, Maria K, Eftichia S (2013) Enhanced levels of the apoptotic BAX/BCL-2 ratio in childrenwith acute lymphoblastic leukemia and high-risk features. Genetics and Molecular Biology 36: 7-11.

9. Peter B, Hermann K, Arend V, Cornelia E, Emilia S, et al. (2014) Monitoring of Minimal Residual Disease After Allogeneic Stem-Cell Transplantation in Relapsed Childhood Acute Lymphoblastic Leukemia Allows for the Identification of Impending Relapse: Results of the ALL-BFM-SCT 2003 Trial. JCO 33: 9747v1.

10. Khan N, Cisterne A, Devidas M, Shuster J, Hunger SP, et al. (2008) Expression of CD44, but not CD44v6, predicts relapse in children with B cell progenitor acute lymphoblastic leukemia lacking adverse or favorable genetics. Leukemia\& Lymphoma 49: 710-718.

11. Wu S, Fischer L, Gökbuget N, Schwartz S, Burmeister T, et al. (2010) Expression of interleukin 15 in primary adult acute lymphoblastic leukemia. Cancer 116: 387-392.

12. Reichard KK, Kang H, Robinett S (2011) Pediatric B-lymphoblastic leukemia with RUNX amplification: clinicopathologic study of eight cases. Mod Pathol 24: 1606-1611.

13. Cooper SL, Brown PA2 (2015) Treatment of pediatric acute lymphoblastic leukemia. Pediatr Clin North Am 62: 61-73.

14. Hafiz MG, Mannan MA (2007) Serum lactate dehydrogenase level in childhood acute lymphoblastic leukemia. Bangladesh Med Res Counc Bull 33: 88-91.

15. Hunger SP, Lu X, Devidas M, Camitta BM, Gaynon PS, et al. (2012) Improved survival for children and adolescents with acute lymphoblastic leukemia between 1990 and 2005: a report from the children's oncology group. J Clin Oncol 30: 1663-1669.

16. Scott LM (2013) Lymphoid malignancies: Another face to the Janus kinases. Blood Rev 27: 63-70.

17. Abdollah B, Ali G, Lueisa T (2014) Association of cytogenetics and immunophenotype in prognosis of children with acute lymphoblastic leukemia: Literature Review. Reviews in clinical medicine 1: 2-6.

18. Zhang J, Ding L, Holmfeldt L, Wu G, Heatley SL, et al. (2012) The genetic basis of early T-cell precursor acute lymphoblastic leukaemia. Nature 481: 157-163.

19. Bachir F, Bennani S, Lahjouji A, Cherkaoui S, Harif M, et al. (2009) Characterization of acute lymphoblastic leukemia subtypes in moroccan children. Int J Pediatr 2009: 674801.

20. Supriyadi E, Veerman A, Ignatius, Peter M, Jacqueline C (2012) Myeloid Antigen Expression in Childhood Acute Lymphoblastic Leukemia and Its Relevance for Clinical Outcome in Indonesian ALL-2006 Protocol. Journal of Oncology.

21. Shrestha S, Shrestha J, Pun C, Pathak T, Bastola S, et al. (2013) Immunophenotypic study of acute leukemia by flow cytometry at BPKMCH. Journal of Pathology of Nepal 3: 345-350.

22. Belurkar S, Mantravadi H, Manohar C, Kurien A (2013) Correlation of morphologic and cytochemical diagnosis with flowcytometric analysis in acute leukemia. J Cancer Res Ther 9: 71-79.

23. Ramyar A, Shafiei M, Rezaei N, Asgarian-Omran H, Esfahani SA, et al. (2009) Cytologic phenotypes of B-cell acute lymphoblastic leukemia-a single center study. Iran J Allergy Asthma Immunol 8: 99-106.

24. Chang G, Zhang H, Wang J, Zhang $Y, X u ~ H$, et al. (2013) CD44 targets Wnt/Bcatenin pathway to mediate the proliferation of K562 cells. Cancer Cell Int 13: 117

25. Ahmed MI, Hassab HM (2008) Study of soluble CD44 and its expression by mononuclear cells in children with acute lymphoblastic leukemia: its relation to prognostic factors. Egypt J Immunol 15: 101-111.

26. Kamazani F, Gholamreza B, Mahnaz A, Shahram V, Zahra A (2014) The Expression and Prognostic Impact of CD95 Death Receptor and CD20, CD34 and CD44 Differentiation Markers in Pediatric Acute Lymphoblastic Leukemia Iran J Pediatr 24: 371-380.

27. Elsharkawy N, Hamdy N, Attia E, Ghaleb F, Abdel Ghany N, et al. (2003) CD44 Expression and Soluble CD44 as a potential Marker of tumor Load in Pediatric Acute Leukemia. Journal of the Egyptian Nat. Cancer Inst 129-135.

28. Prochazka L, Tesarik R, Turanek J (2014) Regulation of alternative splicing of CD44 in cancer. Cell Signal 26: 2234-2239.

29. Stivarou T, Patsavoudi E (2015) Extracellular molecules involved in cancer cell invasion. Cancers (Basel) 7: 238-265

30. Zac C, Leah M, Francoise M, David M, Jeffrey M, et al. (2014) Epigenetic deregulation in pediatric acute lymphoblastic leukemia. Epigenetics 9: 459-467.

31. Bendall LJ, Nilsson SK, Khan NI, James A, Bonnet C, et al. (2004) Role of CD44 variant exon 6 in acute lymphoblastic leukaemia: association with altered bone marrow localisation and increased tumour burden. Leukemia 18: 1308-1311.

32. Kyueng W, Min Y, Ha O, Chan K, Park S, et al. (2011) CD44s and CD44v6 Are Predominantly Expressed in the Non-germinal Center B-Cell-like Type of Diffuse Large B-Cell Lymphomas. The Korean Journal of Pathology 45: 589-595.

33. Todaro M, Gaggianesi M, Catalano V, Benfante A, lovino F, et al. (2014) CD44v6 is a marker of constitutive and reprogrammed cancer stem cells driving colon cancer metastasis. Cell Stem Cell 14: 342-356. 